\title{
THE RELATIONSHIP BETWEEN SOME POVERTY INDICATORS AND FOOD SECURITY IN A RURAL AREA IN EL-SHARKIA GOVERNORATE
}

(Received: 25.11.2016)

\author{
By \\ M.H. Nawar, S. M. Nasrt and A.A. Nasr \\ Rural Sociology and Agriculture Extension Department, Faculty of Agriculture, \\ Cairo University, Giza, Egypt
}

\begin{abstract}
Poverty is still one of the crucial issues in social sciences, as well as, being one of the most controversial issues among scientists and specialists. Social scientists have been interested in studying the indicators and issues associated with poverty. Additionally, studies have focused on food security as one of the important issues that maybe affected by, or linked to poverty. Hence, the present study aims at identifying the relationship between poverty and food security. The focus in this paper is to examine if there is a relationship between poverty and food security and the degree to which indicators related to the household socio-economic characteristics is related to its food security. Farm-level data were collected from 325 participants, in Sharkia Governorate in (Tarot Village) employing Morgan's equation using a structured questionnaire. Results showed that, there is a significant negative relationship with spending on food and food security, during Feb. 2015 so we can say there is a relationship between several socio-economic characteristics of the household and its food security.
\end{abstract}

Key words: poverty, food security, El-sharkia.

$$
\begin{aligned}
& \text { العلاقة بين بعض مؤشرات الفقر ومستويات الأمن الغذائي بقرية طاروط محافظة الثرقية } \\
& \text { محمد حلمي نوار ـ سوزان محي الدين نصرت ـ أسماء أحمد نصر } \\
& \text { قسم الاجتماع الريفي والإرشاد الزراعي- كلية الزراعة ـ جامعة القاهرة ـ الجيزة }
\end{aligned}
$$

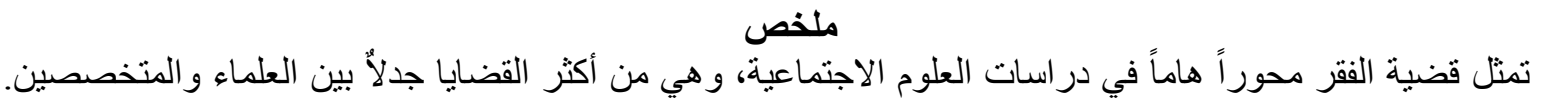

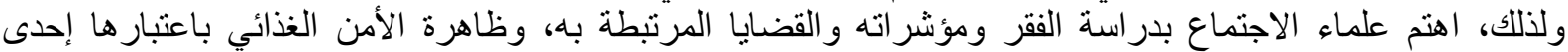

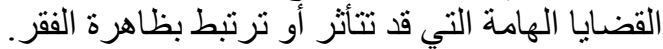

استهدف هذا البحث التعرف على العلاقة ترثة بين مؤشرات الفقر ومستويات الأمن الغذائي. تم اجر اء البحث بقرية طاروط

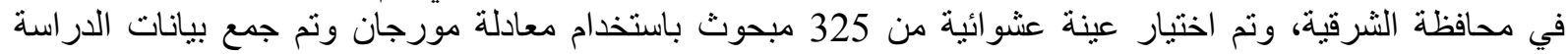

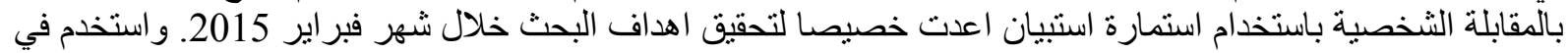

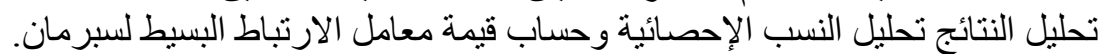

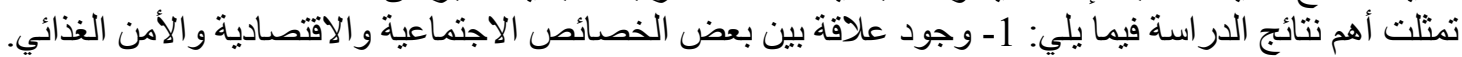

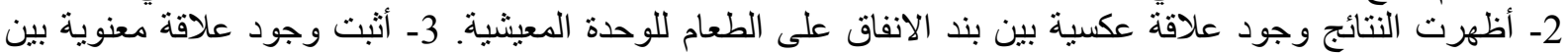
مؤشر ات الفقر و الأمن الغذائي. 


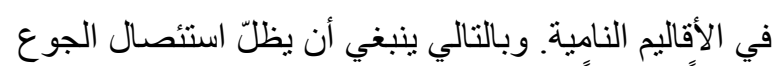

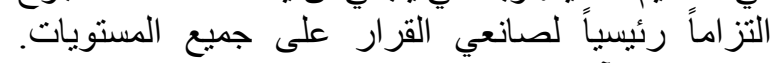

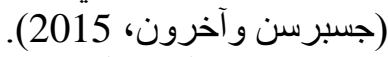

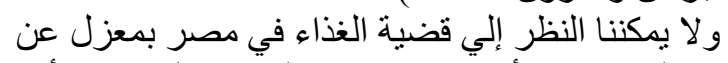

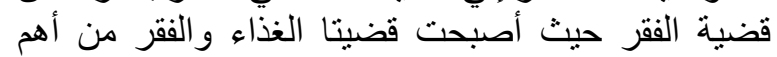

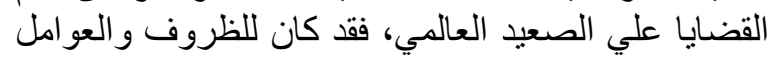

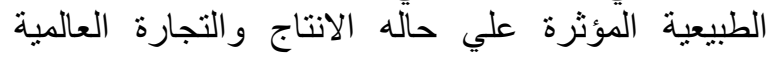

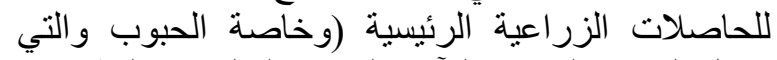

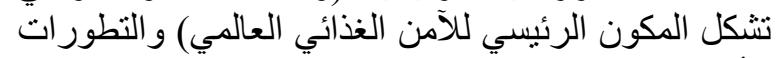

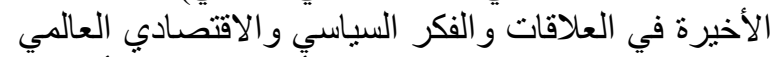

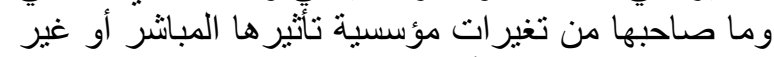

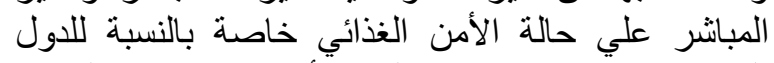

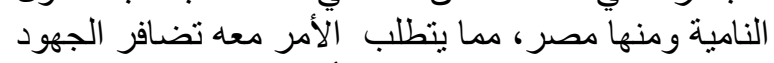

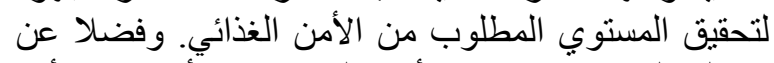

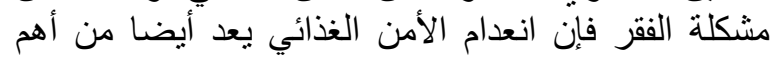

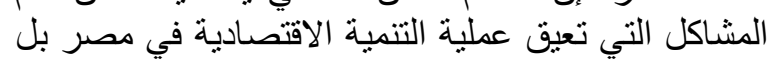

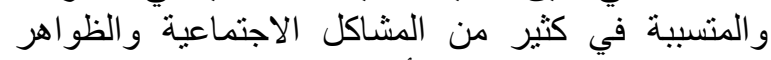

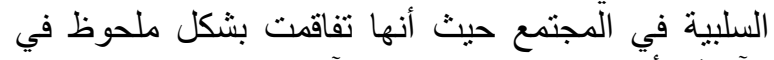

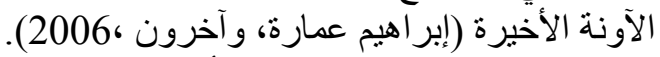

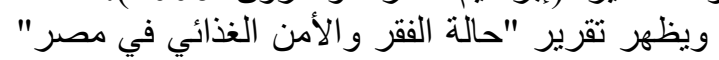

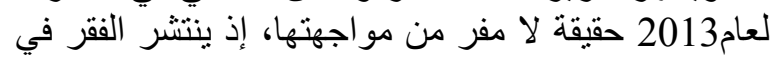

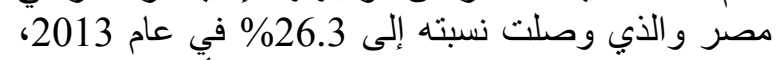
و هو ما يعني إهدار الحق في الغذاء على الأقلّل لنحو 13.7

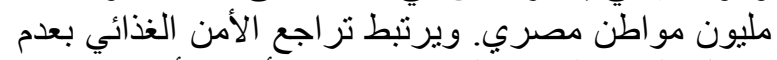

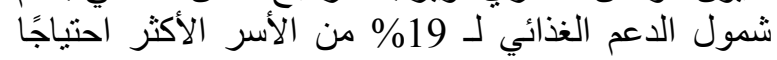

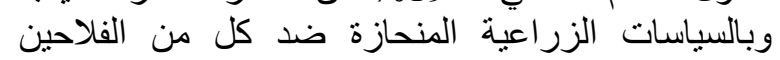

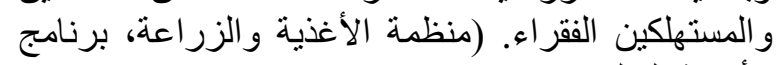

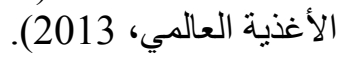

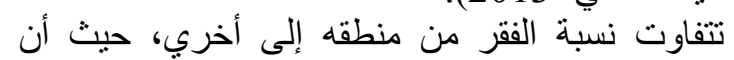

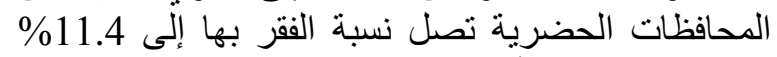

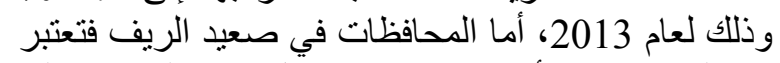

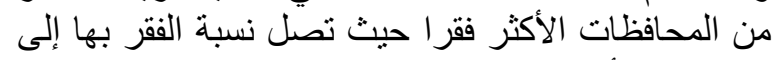

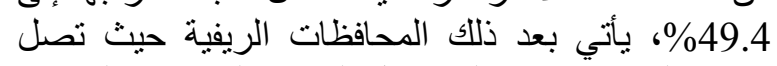

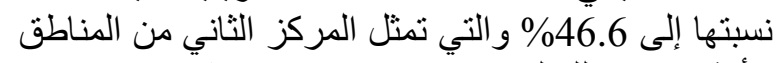

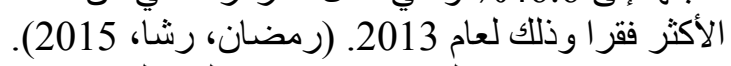

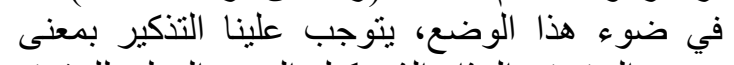

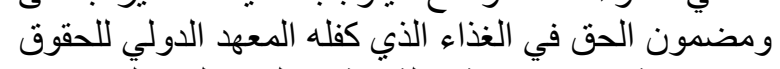

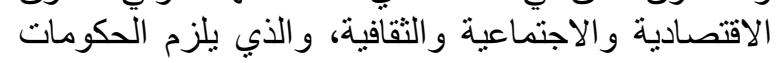

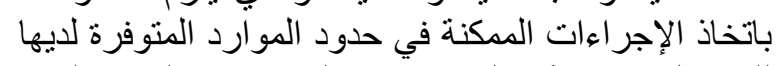

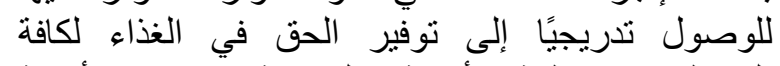

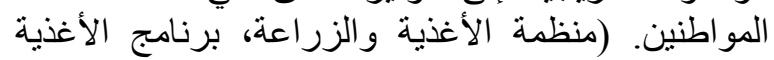

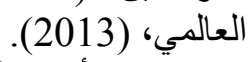
ويمكننا أن نخلص إلى أن الأسباب الجذرية لانعدام

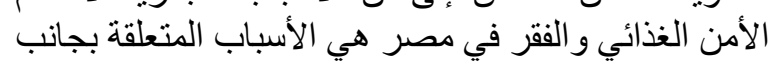

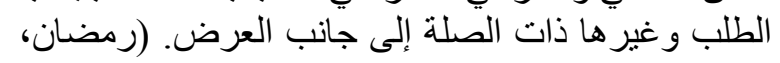

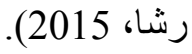

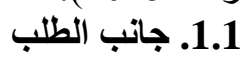

ارتفع عدد السكان الكلي في مصر خلالب السنوات السنات العشر الأخيرة بمتوسط 1.7\% سنويا، بينما وصل معدل

\section{1 - 1.المقدمة}

يظل هدف القضاء على الفقر بجميع أشكاله في

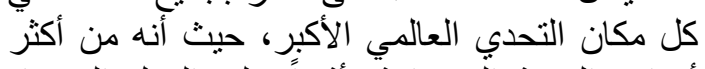

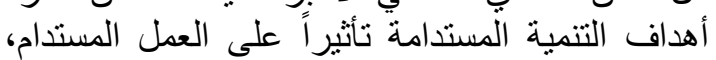

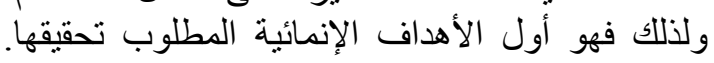
كان بوسع العالم الاحتفال ببلوغ الإنغانية الغاية التي نصلوبت عليها

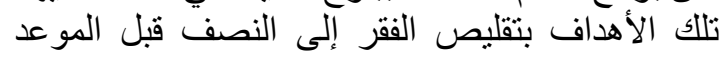
النهائي المحدد عام2015، ولكن على عدم الوفاء كلية بهذا

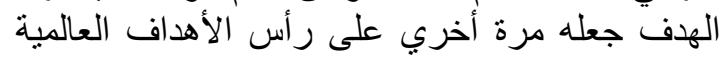

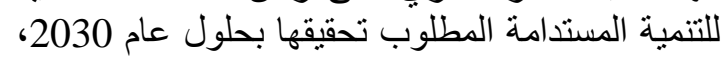
ويكمن هدف القضاء على الفقر في صميم كل ما يقدام من جهود للنهوض بالكر امة الإنسانية و التنمية الشاملة ملئة

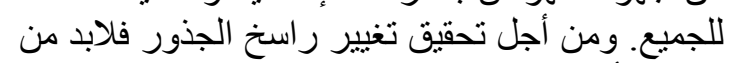

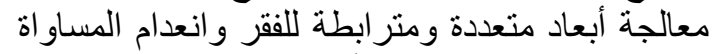

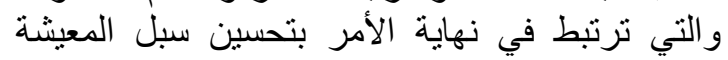

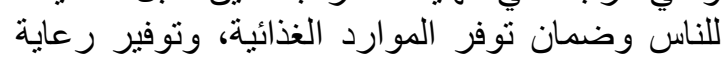
صحية أفضل، ومستويات معيشة أعلى الثلى (جسبرسن

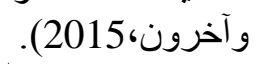

ونوضح تقارير المتابعة والتقييم المعنية بمدي تحقيق

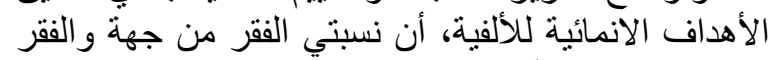

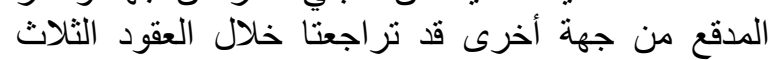

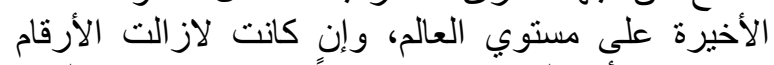

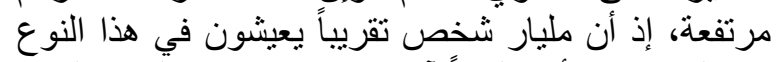

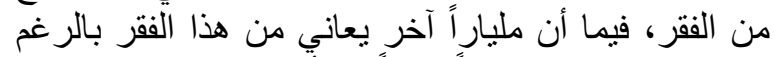

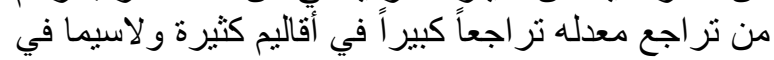

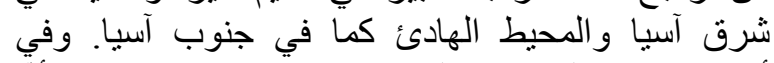

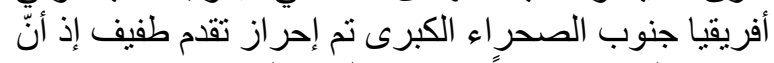

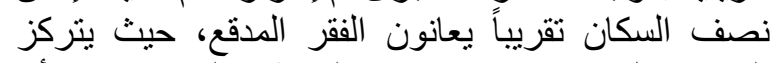

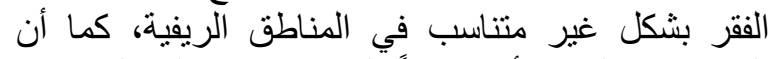

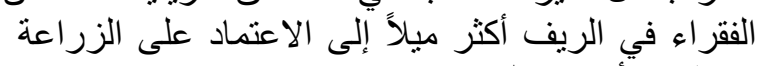

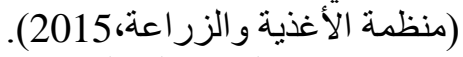
ويصاحب الفقر غالبا التخذية والصحة التحة الرديئتين نتيجة

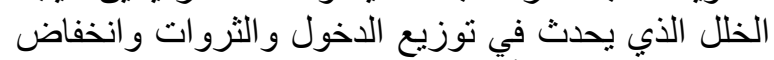

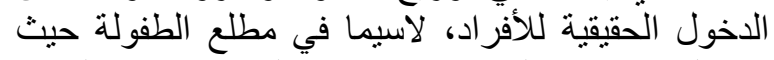

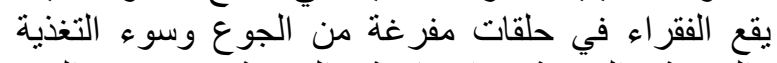

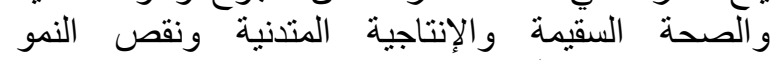

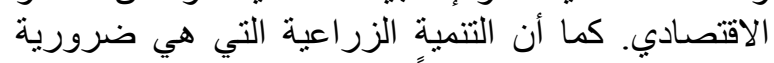

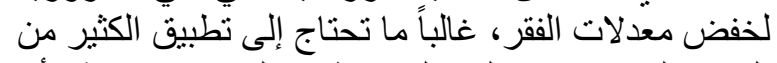

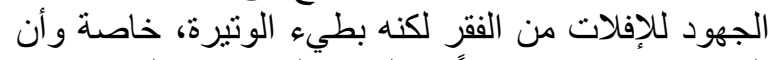

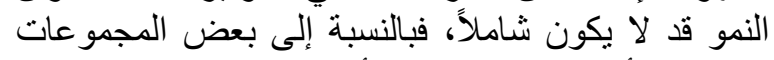

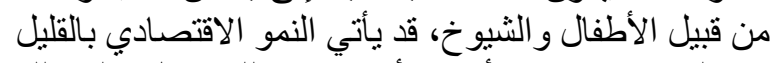

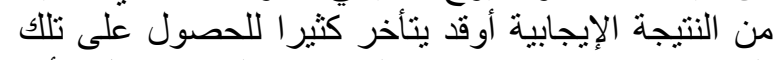

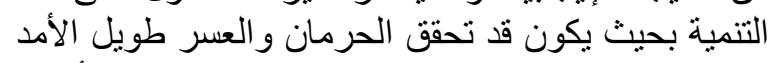

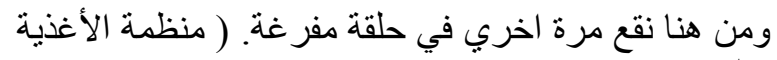

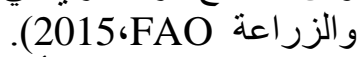

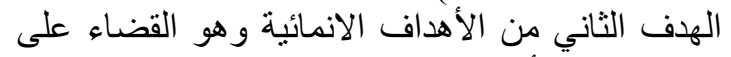

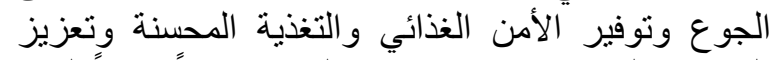

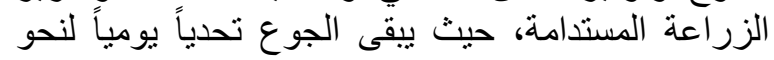

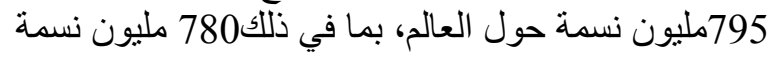


كما يتضح لنا من جدول رقم (1) أن أعلي النسب هي الإنب

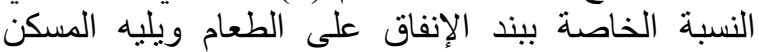
ومستلزماته ويليه خدمات الرعاية الصحية يليه باقي بنود بله

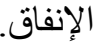

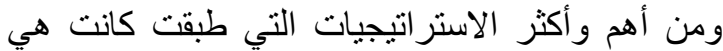
خفض استهلاك الغذاء عالي الثمن و هي الاستر اتيجية التي التي التي التي

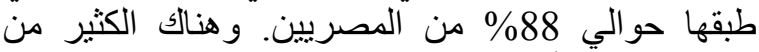
الاستر اتيجيات أيضا منها خفض الحصة الحصة اليومية من الغذاء

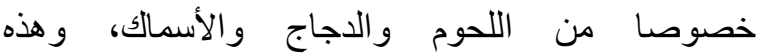

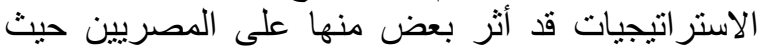
أدي إلى ارتفاع انعدام الأمن الغذائي وارتفاع نسبة السمنة

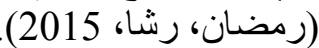

نمو السكان الحالي في مصر إلى نحو 2.6\% من كل عام عام.

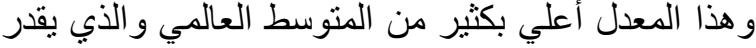
بنحو 1.2\% كل عام. لهذا فقد ارتفع عدد السكان في ماتي

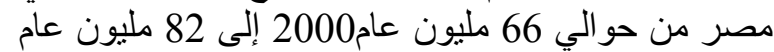

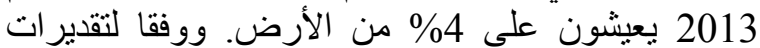

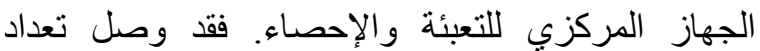
السكان في مصر إلى حوالي ل1 ومليون في عام 2016.

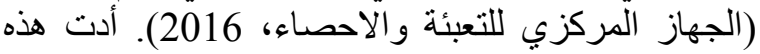

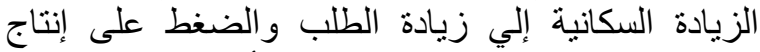

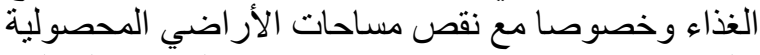
(المنزرعة) و وانخفاض مستوي الإنتاج الغذائي المحلي.

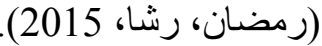

جدول (1): بنود الإنفاق الأسري لعام 2013/2012 الخاص ببحث الدخل والإنفاق والاستهلاك.

\begin{tabular}{|c|c|c|c|}
\hline \multicolumn{3}{|c|}{$2013 / 2012$} & \multirow{2}{*}{ مجموعات الإنفاق } \\
\hline إجمالي & ريف & 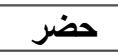 & \\
\hline 37.6 & 41.4 & 34 & الطعام والمشروبات غير الكحولية \\
\hline 4.1 & 4.3 & 3.8 & المشروبات الكحولية والاخان والمكيفات \\
\hline 5.4 & 5.8 & 5.0 & الملابس والأقمشة وأغطية القدم \\
\hline 18.1 & 16.9 & 19.3 & المسكن ومستلزماته (مياه، كهرباء، غاز ، وقود، أخرى) \\
\hline 4.1 & 4.1 & 4.1 & الأثثاث والتجهيزات والمعدات المنزلية وأعمال الصياتة الاعتيادية \\
\hline 9.2 & 9.6 & 8.9 & الخدمات الرعاية الصحية \\
\hline 5.2 & 4.1 & 6.3 & الانتقالات و النقل \\
\hline 2.3 & 1.8 & 2.7 & 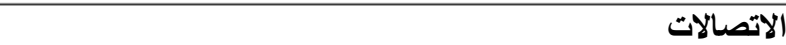 \\
\hline 2.0 & 1.8 & 2.2 & الثقافة و الترفيه \\
\hline 4.0 & 2.5 & 5.4 & 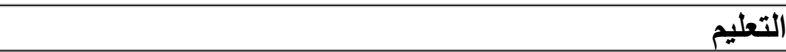 \\
\hline 3.1 & 2.9 & 3.2 & السلع والخدمات المتنوعة \\
\hline 98.7 & 98.3 & 99.1 & إجمالي الاستهلاك الفعلي(1) \\
\hline 1.7 & 1.8 & 1.5 & إجمالي التحويلات العينية \\
\hline 97.0 & 96.5 & 97.5 & إجمالي الإنفاق الاستهلاكي \\
\hline 3.0 & 3.5 & 2.5 & المدفوعات التحويلية (إنفاق غير استهلاكي) \\
\hline 100 & 100 & 100 & إجمالي الإنفاق العائلي(2) \\
\hline 15057 & 8326 & 6731 & عدد الأَسر \\
\hline 65169 & 38326 & 26842 & عداد الأفراد \\
\hline
\end{tabular}

(1) الاستهلاك الفعلي يتضمن نسبة إجمالي الإنفاق الاستهلاكي + نسبة إجمالي التحويلات العينية.

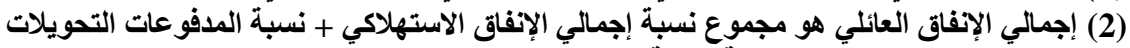
المصدر :الجهاز المركزي للتعبئة العامة والاحصاء. (2012 /2013)، بحث الاخل والإنفاق والاستهلاكل.

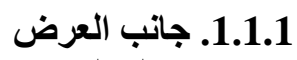

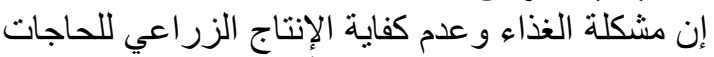

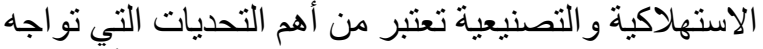

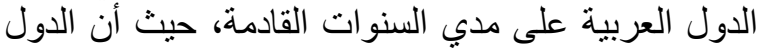

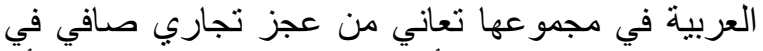

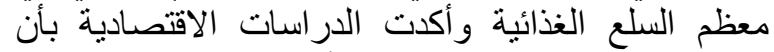

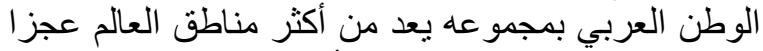

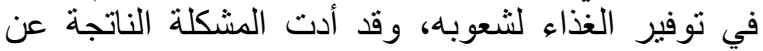

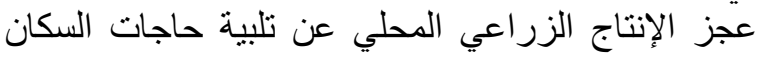

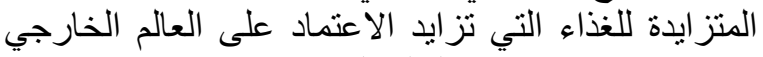
في توفير احتياجاته من السلع الغذائية . لإنان
أخبر ا، يمكننا القول إن الأحداث السياسية التي حدثت في

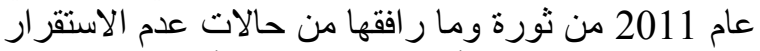

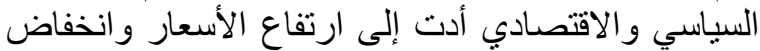

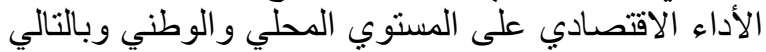

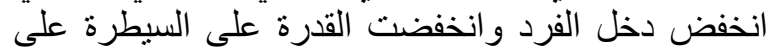

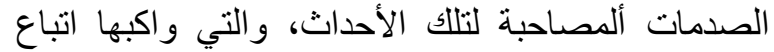

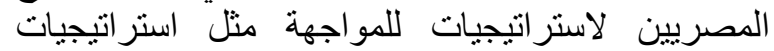
التكيف وتغيير النظام الغذائي.

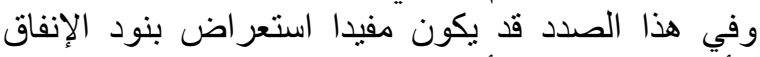
الأسري في الفترة الأخيرة من خلال جدول مفند (1): 
3.1.3. تحديد العلاقة بين بعض الخصائص الاجتماعية والاقتصادية وبند الإنفات على الطعام للوحدة الطئ المعيشية.

\section{4. فروض البحث}

ولتحقيق الهدف الثاني والثالث والبحث الرابع تم صياغة

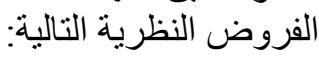

1.4. يوجد علاقة بين بعضة الإنة الخصائص الاجنماعية و الاقتصادية و الأمن الغذائي للوحدة المعيشية لإندانية

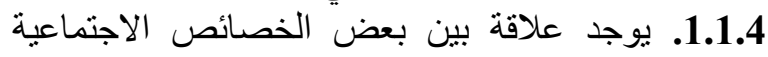
و الاقتصادية وبند الإنفاق الكلي للوحدة المعيشية الإنية

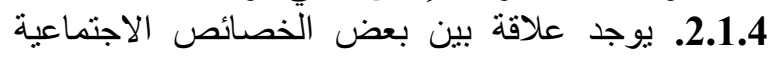

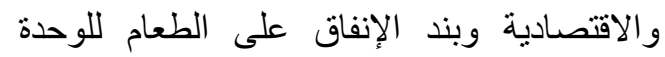

$$
\text { المعيشية }
$$

\section{5. 5 الطريقة البحثية}

تعد هذه الدر اسة من الدراسات الوصفية التحليلية، حيث الطئ

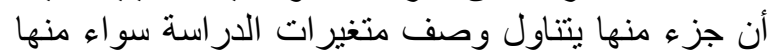

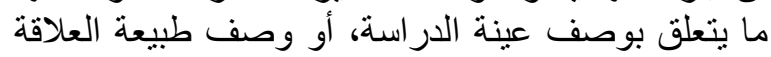

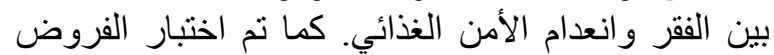

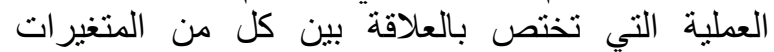

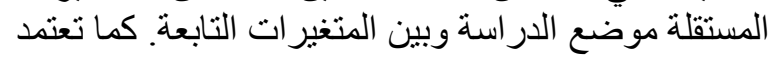

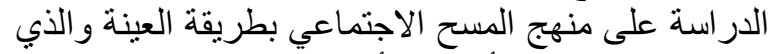
تم اختياره لملاءمته لأهداف و أغر اض الداع الدراسة.

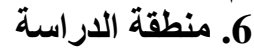

أجريت الدراسة بمحافظة الشرقية حيث تقع ضمن الإنة

الإقليم التخطيطي الثالث الذي يضم محافظات القناة وسيناء

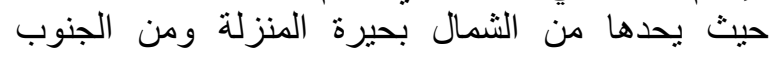

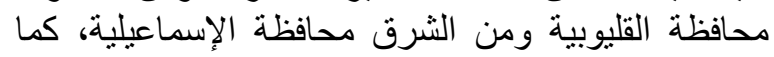

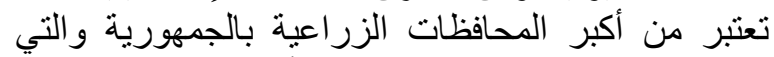

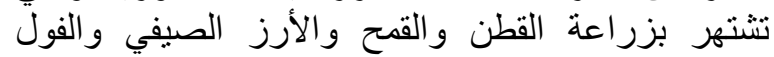

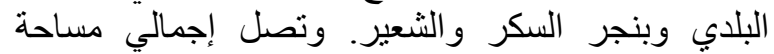
الأراضي المزروعة حوالي 851.58 ألف فئلفير فدان وتساهم

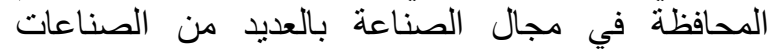

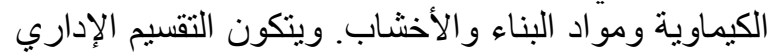

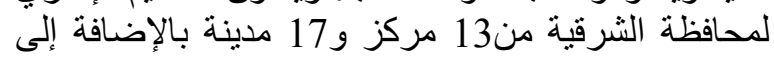

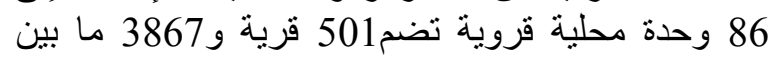

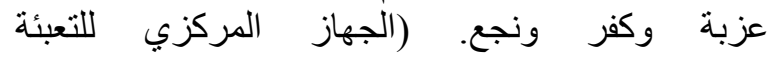

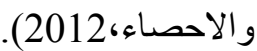
7. أدوات جمع البيانات

اعتمدت الدر اسة البئنات على البيانات الميدانية التي تم جمعها

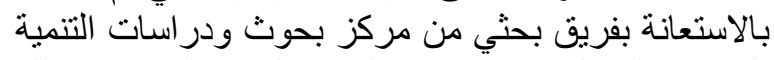

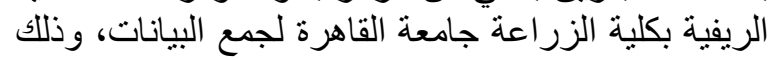

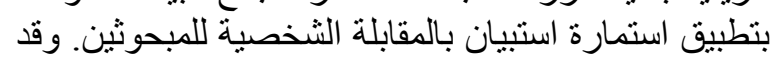

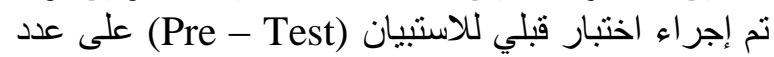

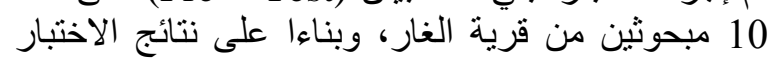

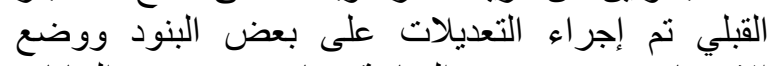

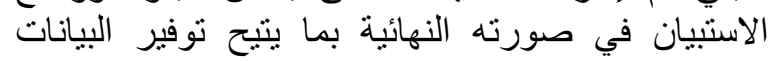
المطلوبة لاختبار الفروض. وقد تم جمع البيانات النهائية
هناك الكثير من التحديات التي تواجه مصر ومن هذه فئه

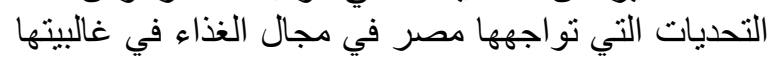

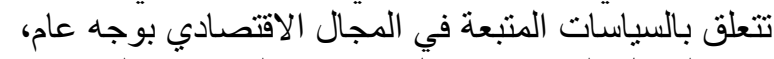

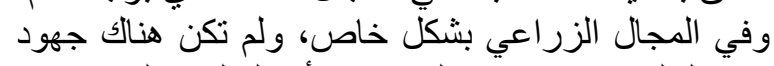
جادة لتقليص حجم هذه التحديات، أو التغلب التب عليها.

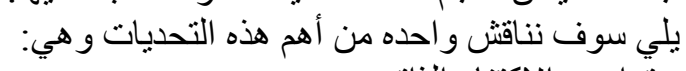

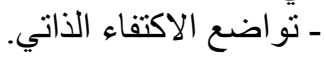
تبين نتائج الدراسة بالفترة من عاد الفئ 2000 وحتى 2010

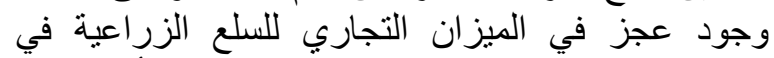

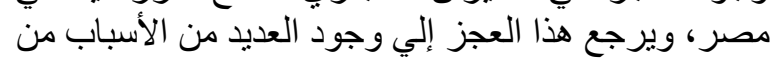

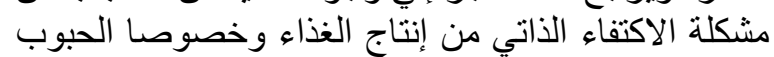

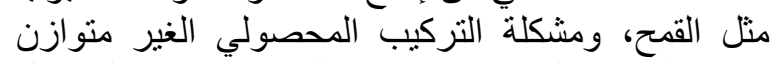

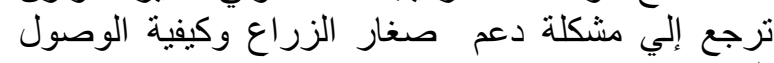

ذكرت رشا رمضان (2015 ) أن التحديات التي

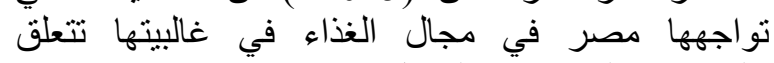

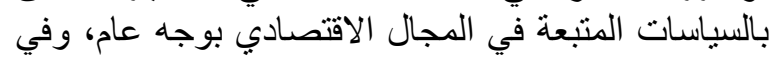

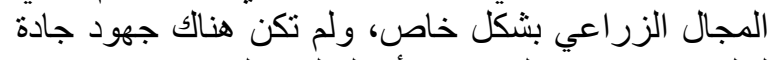
لتقليص حجم هذّة التحديات، أو التغلب علئ عنها.

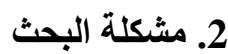

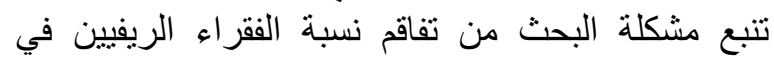

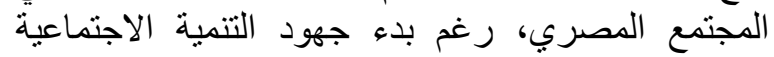
والاقتصادية في مصر منذ الستينات لمحاربة الفقر الذية الذئية تفاقمت معهة أيضّا مشكلة انعدام الأمن الغذائي.

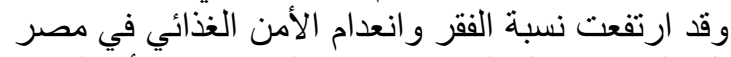

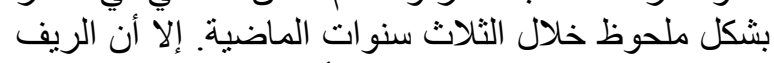

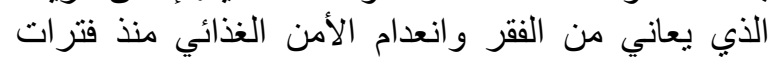

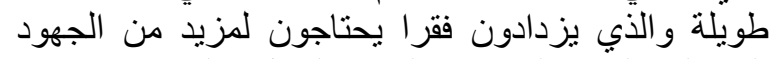

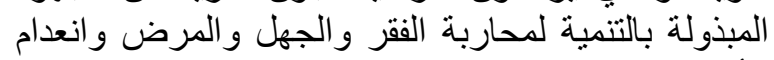
الأمن الغذائي.

تلبلورت من خلال الفائ ما سبق مشكلة البحث في السعي

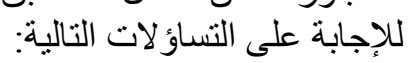

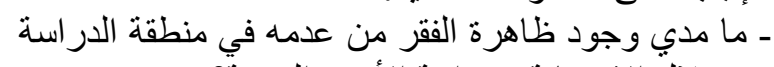
من خلال الاستعانة بميز انية الأسرة الريفية الفيّ؟

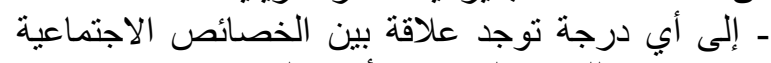

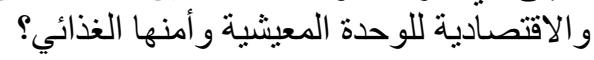

\section{3}

في ضوء العرض السابق لمشكلة البحث يمكن صياغة

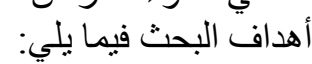

1.3. التعرف "على نمط الإنفاق العائلي الأسر الريفية سنويا

1.1.3. تحديد العلاقة بين بعض الخصائص الاجتماعية

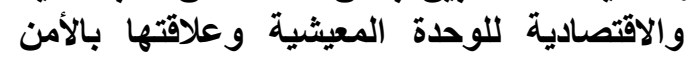
الغذائي

2.1.3. تحديد العلاقة بين بعض الخصائص الاجتماعية العابية والاقتصادية ويند الإنفاق الكلي للوحدة المعيشية الخدية 


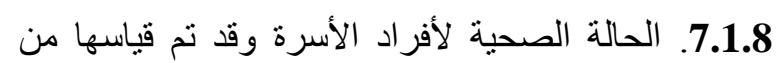

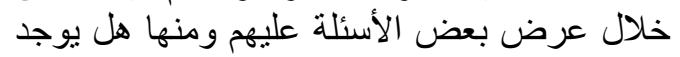

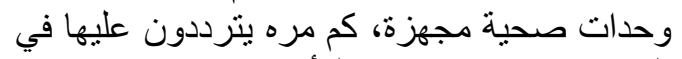

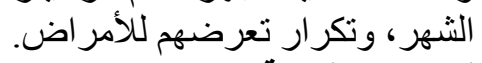
ثانيا : المتغيرات التابعة

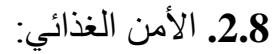

ويتم قياسه من خلان الأل عدة أبعاد أساسية تشمل:

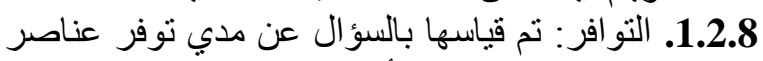

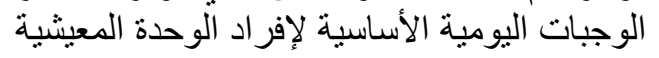

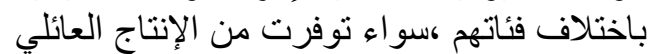

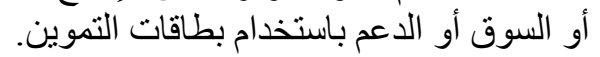

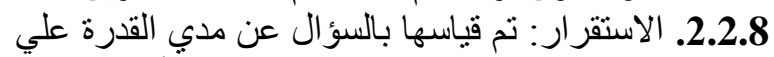

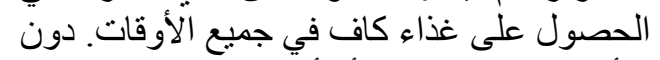

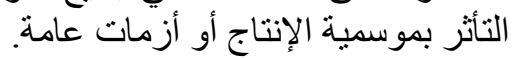
الاستخدام: نم قياسها بالسؤال الزال عن كيفية استخدام

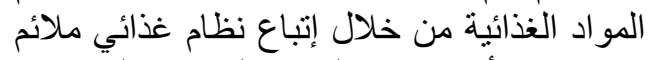

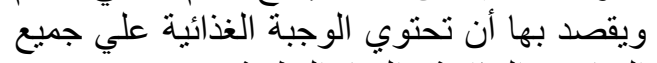

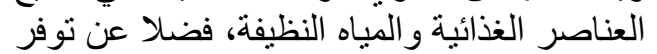
الرعاية الصحية اللازمة لكل فئَّ.

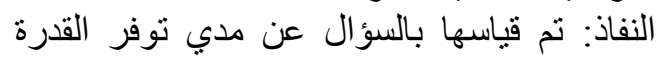

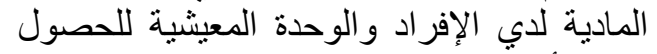
علي الأطعمة المناسبة لإتباع نظام غذائي مغذي. لإني.

\section{9. النتائج والمناقشة}

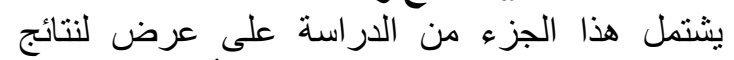

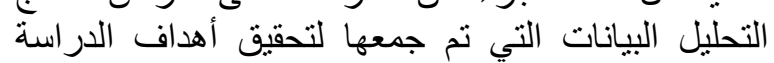

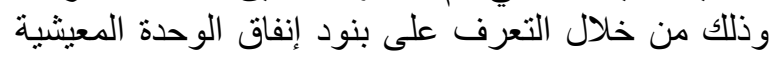

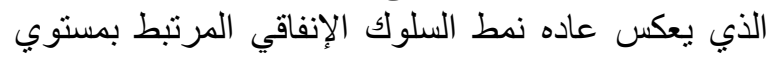

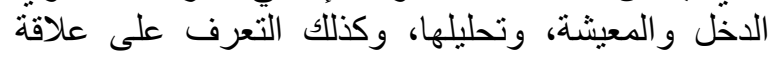
بعض الخصائص الاجتماعية والاقتصادية ولانية وعلاقتها بالأمن الغذائي للوحدة المعيشية.

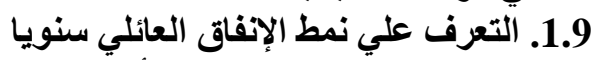

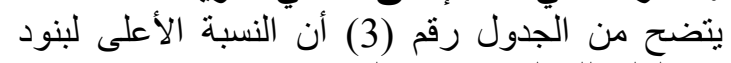

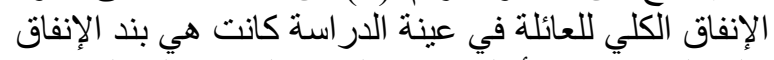

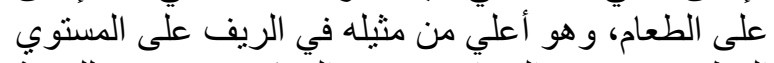

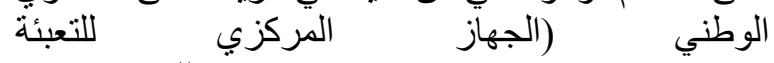

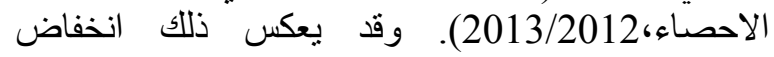

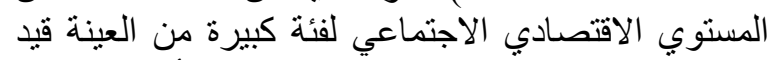

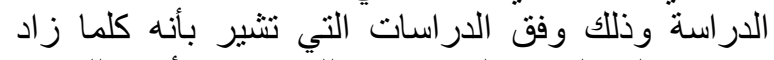

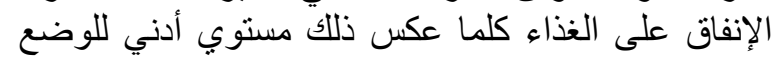

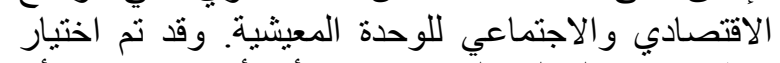

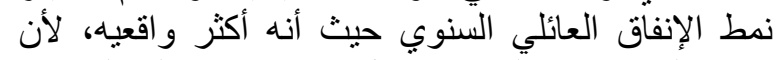

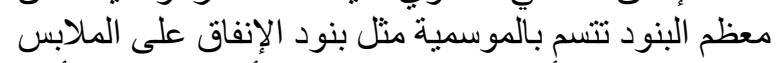

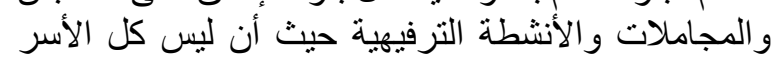

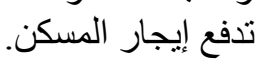

للار اسة خلال شهر فبراير 2015بقرية طاروط من عينة

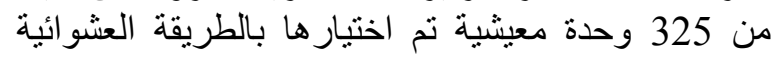

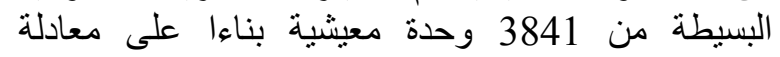

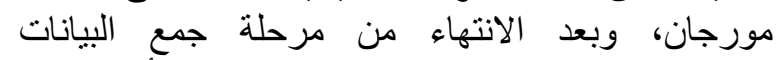

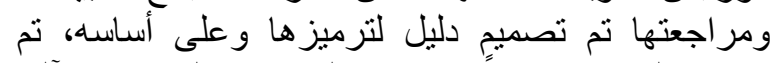

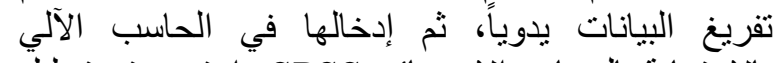

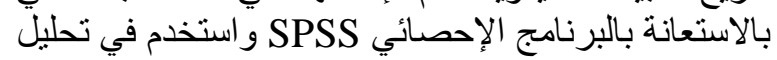

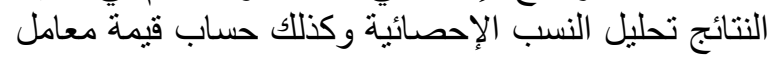

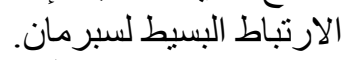

8. التعريفات الإجرائية والمناهج المستخدمة المبانية في البحث أولا: المتغيرات المستقلة الاجلة

شملت المتغير ات المستخدمة لتحقيق أهداف الدر اسة ما يلي؛

1.8. النوع الاجتماعي للمبحوث داخل الوحدة المعيشية:

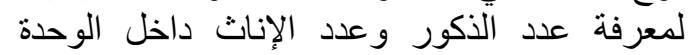
المعيشية.

1.1.8. لوحدة المعيشية: هي التي تتكون من فرد أو أكثر

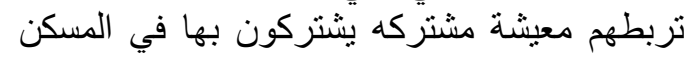

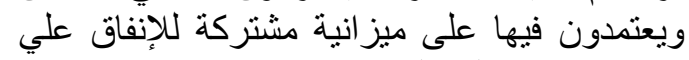
جو انب حياتهم المختلفة.

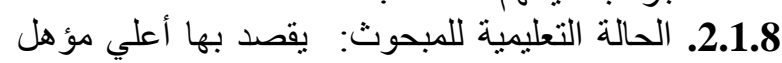

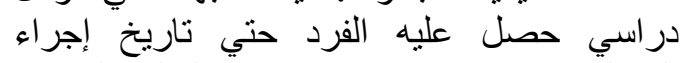
المقابلة. وهي مقاسة بعدد سنوات التعليم الرسمي الرئ التي مر بها التفرد.

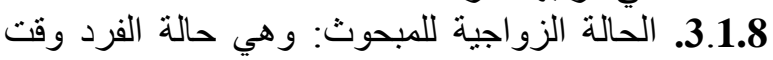

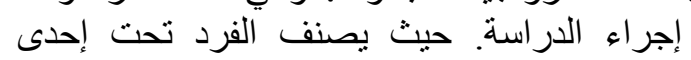

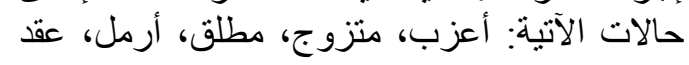

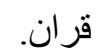
4.1.8 رب الأسرة: هو الفرد الذي تعتبره الأسرة رئيساً

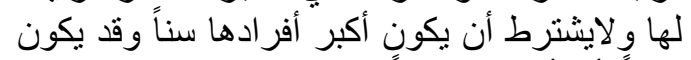

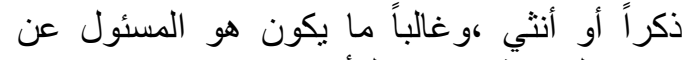
توجيه السياسة الإنفاقيه للأسرة.

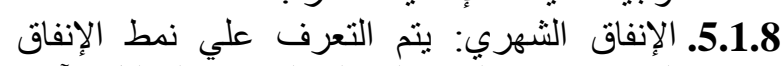

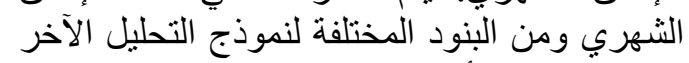

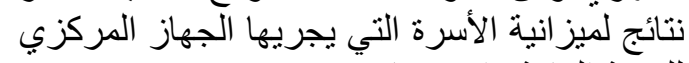

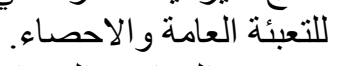

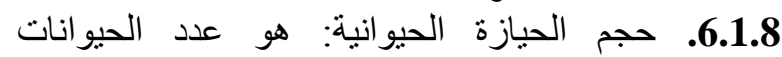

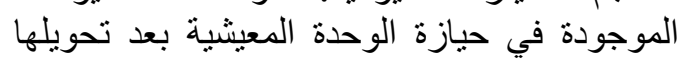

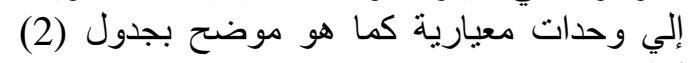

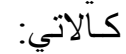

\begin{tabular}{|c|c|}
\hline 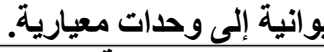 & 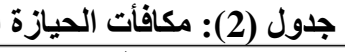 \\
\hline الوحدة الحيوانية & نوع الحيوان/الطائر \\
\hline 1وحدة معيارية & البقزة \\
\hline 1.3وحدة معيارية & الجاموس \\
\hline 1وحدة معيارية & كل خمسة رؤوس الأغنام \\
\hline 1وحدة معيارية & 750 750ئر \\
\hline
\end{tabular}
الاققى، 2001. 
الفرض الإحصائي، ووجود علاقة طردية وإن كانت ضعيفة بين المتغيرين.

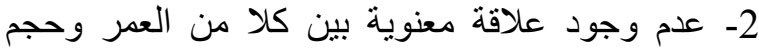

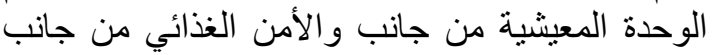

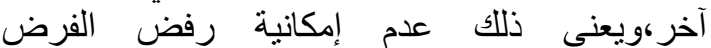
الإحصائي. بناءاً على هذه النتائج يمكن رفض الفرض الإحصائي

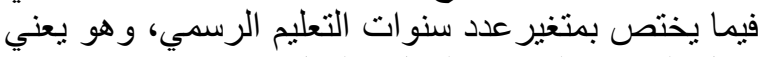

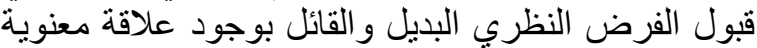

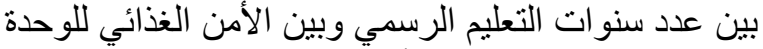

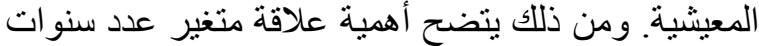

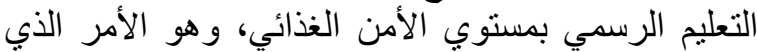

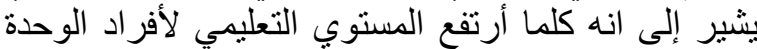

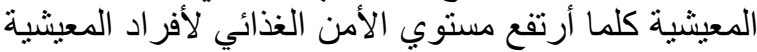
وقد يعود ذللك إلى أن ارتفاع مستوي التعليم يصناحبه

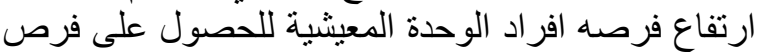

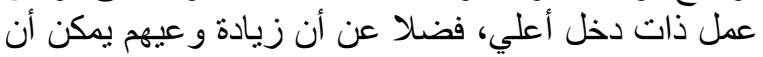

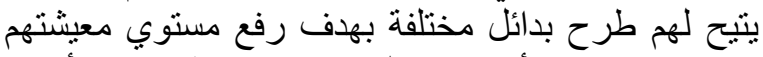

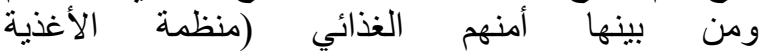
و الزر اعة،2015). ب. العلاقة بين بعض الخصائص الاقتصادية والأمن الغذائي

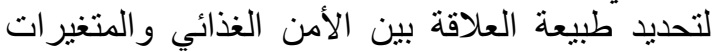

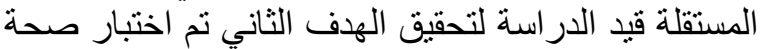

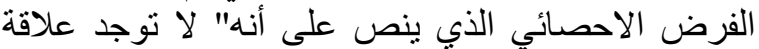

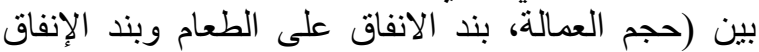
الكلي وحجم الحيازة الحيوانية وحجم حيازة الأراضي)

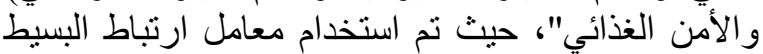
لبيرسون لاختبار صحة هذه العلاقة.

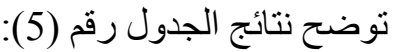
1- وجود علاقة ارتباطية معنوية بين حجم العمالة للوحدة الودئ

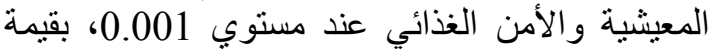
معامل ارتباط 0.164 ويعني ذلك عدم إمكانية قبول

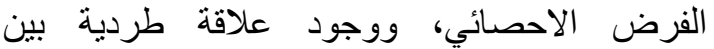

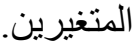
2- وجود علاقة ارتباطية معنوية بين بند الإنفاق على الإنى

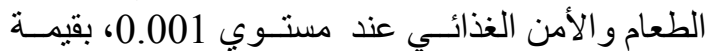

جدول رقم (3): بنود الإنفاق العائلي السنوي.

\begin{tabular}{|c|c|}
\hline \% لبند الإنفاق العائلي & بنود الإنفاق العائلي سنويا \\
\hline 73.25 & الإنفاق على الطعام \\
\hline 1.02 & ملابس \\
\hline 0.86 & تعليم \\
\hline 0.68 & إيجار مسكن \\
\hline 5.97 & كهرباء \\
\hline 3.24 & مياه \\
\hline 9.74 & المواصلات \\
\hline 1.91 & علاج وأدوية \\
\hline 0.16 & مجاملات \\
\hline 0.39 & أنشطة ترفيهية \\
\hline 2.78 & نثريـات \\
\hline 0.00 & أخري تذكر \\
\hline 100 & الإجمالي \\
\hline
\end{tabular}

وباستعر اض البيانات في جدول رقم (3) ومقارنتها بجدول رقم (1) السابق ذكره حيث نجد تطابق بين كلا من فن إن

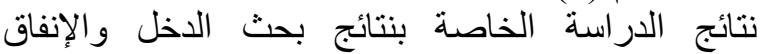

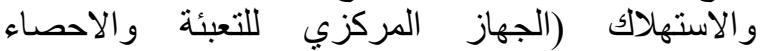

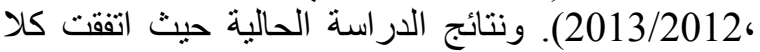

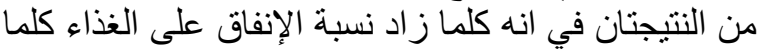

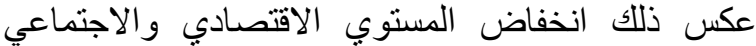

للوحدة المعيشية.

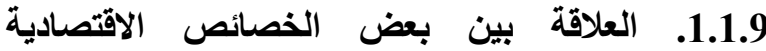
والاجتماعية والأمن الغذائي أ. العلاقة بين بعض الخصائص الاجتماعية والأمن الغذائي الغئي

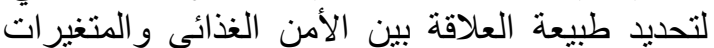

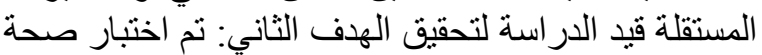

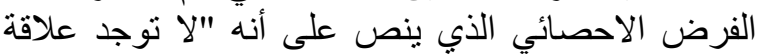

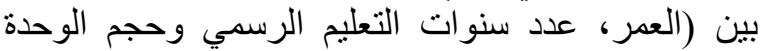

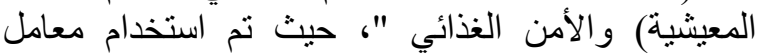
الارنباط البسيط لبيرسون لاختبار صحة هذه العلاقة.

جدول رقم (4): قيم معامل بيرسون للارتباط البسيط بين بعض الخصائص الاجتماعية مع الأمن الغذائي.

\begin{tabular}{|c|c|c|}
\hline مستوي المعنوية المحسوبة & قيمة معامل بيرسون للارتباط البسيط & الخصائص الاجتماعية \\
\hline .496 & .038 & 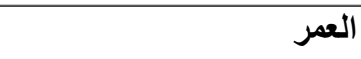 \\
\hline .002 & $.169^{* * *}$ & عدد سنوات التعليم الرسمي \\
\hline .124 & .086 & حجم الوحدة المعيشية \\
\hline
\end{tabular}

المصدر : تحليل بيانات الدراسة.

معامل ارتباط -0.220- ويعني ذللك عدم إمكانية قبول

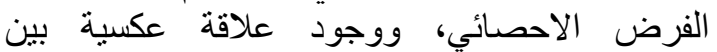

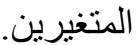

توضح نتائج الجدول رقم (4):

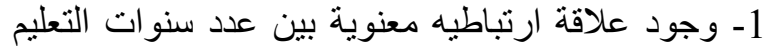

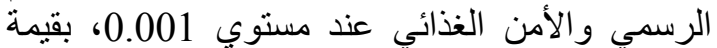
معامل ارتباط 0.169 ويعني ذلك عدم إمكانية قبول 
جدول رقم (5): قيم معامل بيرسون للارتباط البسيط بين بعض الخصائص الاقتصادية مع الأمن الغذائي.

\begin{tabular}{|c|c|c|}
\hline مستوي المعنوية المحسوبة & قيمة معامل بيزسون للارتباط البسيط & الخصائص الاقتصادية \\
\hline .003 & $.164^{* * *}$ & حجم العمالة \\
\hline .000 & $-.220-^{* *}$ & بند الإنفاق على الطعام \\
\hline .603 & .029 & بند الإنفاق الكلي \\
\hline .193 & .073 & حجم الحيازة الحيوانية \\
\hline .051 & .109 & حجم حيازة الأر اضي \\
\hline
\end{tabular}

المصدر: تحليل بيانات الدراسة.

1- وجود علاقة ارتباطيه معنوية بين العمرو بند الإنفاق الكلي عند مستوي

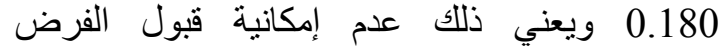
الإحصائي، ووجود علاقة طردية ودية بين المتنغيرين.

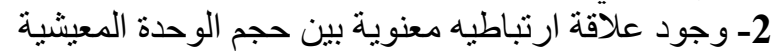

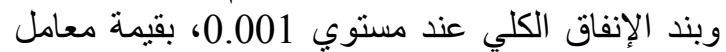

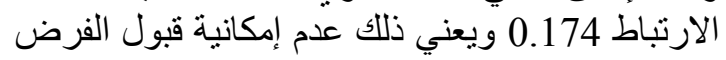
الإحصائي، ووجود علافة طردية بين المتغيرين.

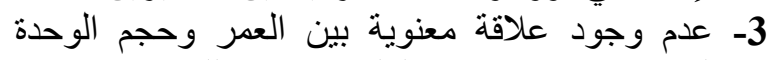
المعينية وبند الإنفاق الكلي ويعني ذللك عدم إمكانية رفضً الفرض الإحصائي.

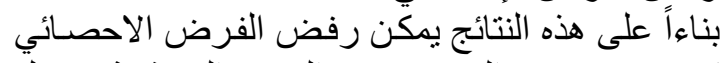

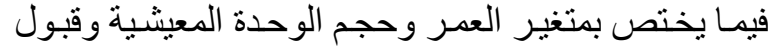

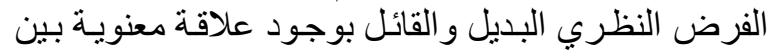

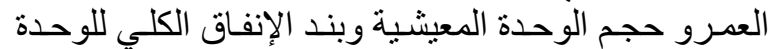

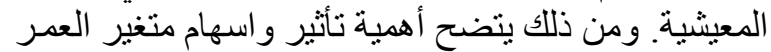

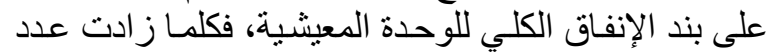

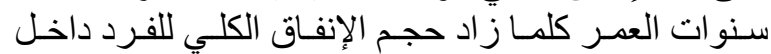

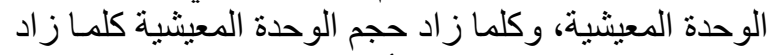

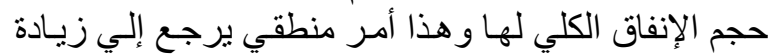

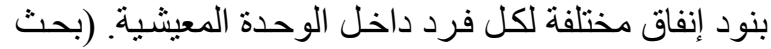

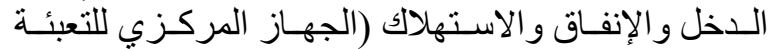
والاحصاء، 2013/2012). ب. العلاقة بين بعض الخصائص الاقتصادية وبند الإنفاق الكلي

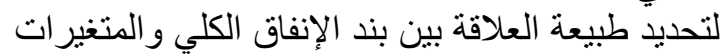

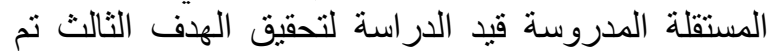

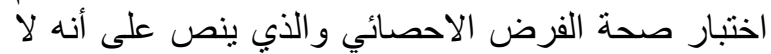

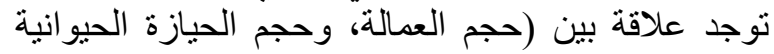

3- عدم وجود علاقة معنوية بين حجم الحيازة الحيوانية

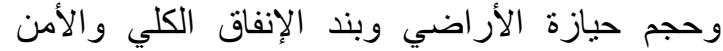

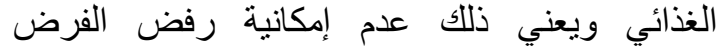
الإحصائي. بناءاً علي هذه النتائج يمكن رفض الفرض الإحصائي

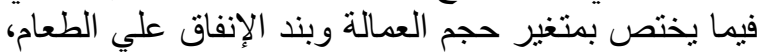

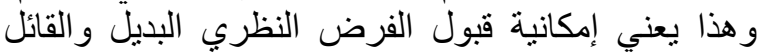

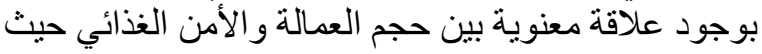

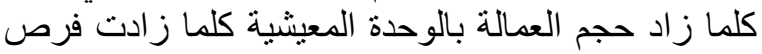

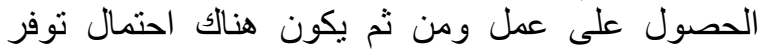

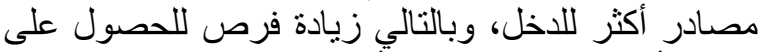

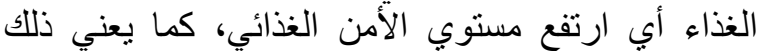

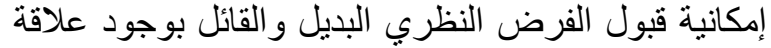

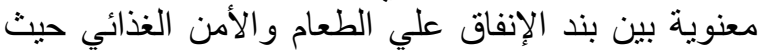

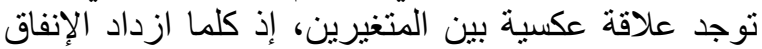

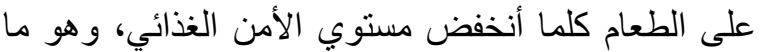

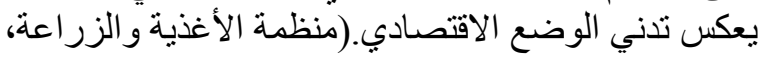

2.1.9. العلاقة بين الخصائص الاقتصادية والاجتماعية

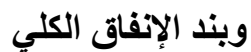
أ. العلاقة بين بعض الخصنائص الاجتماعية وبند الإنفاق الإق الكلي: - العله: لتحديد طبيعة العلاقة بين بند الإنفاق الكلي

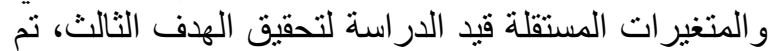

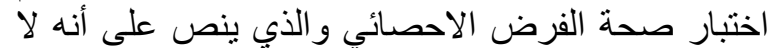

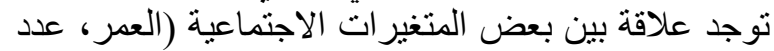

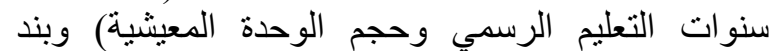

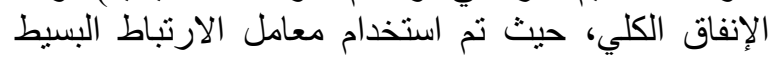

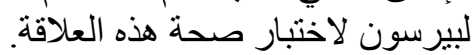
توضح نتائج الجدول رقم (6): جدول رقم (6): قيم معامل بيرسون للارتباط البسيط بين بعض الخصائل الخصائص الاجتماعية وبند الإنفاق الكلي.

\begin{tabular}{|c|c|c|}
\hline مستوي المعنوية المحسوبة & قيمة معامل بيرسون للارتباط البسيط & الخصائص الاجتماعية \\
\hline .001 & $.180^{* *}$ & 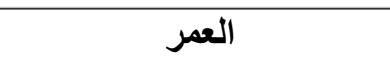 \\
\hline .119 & .087 & عدد سنوات التعليم الرسمي \\
\hline .002 & $.174^{* *}$ & حجم الوحدة المعيشية \\
\hline
\end{tabular}


الأرض من أسمدة ومبيدات و الآلات زر اعية وغير ها مما يؤدي إلى ارتفاع حجم بند الإنفاق الكلي للوحدة الإندات المعيشية

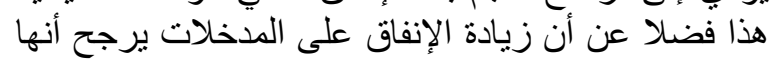

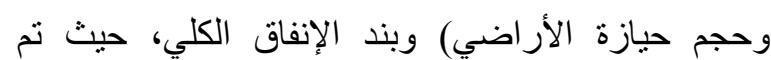

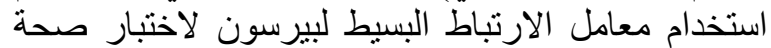

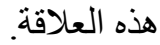

\begin{tabular}{|c|c|c|}
\hline مستوي المعنوية المحسوبة & قيمة معامل بيرسون للارتباط البسيط & الخصائص الاقتصادية \\
\hline .093 & .093 & حجم العمالة \\
\hline .002 & $.169^{* * *}$ & حجم الحيازة \\
\hline
\end{tabular}

المصدر : تحليل بيانات الدراسة.

تعود بزيادة في الدخول التي تخصص أيضا للإنفاق

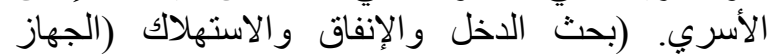
المركزي للتعبئة والاحصاء، الاخلوالإنفاق (2013/2012).

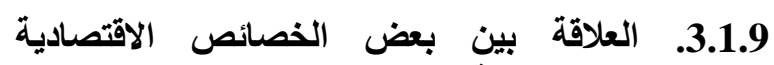

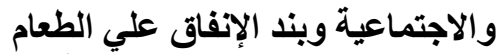

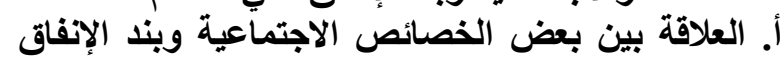

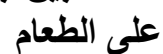
لتحديد طبيعة العلاقة بين بند الإنفاق على الطعام

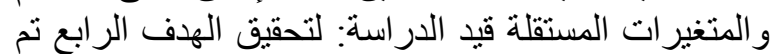

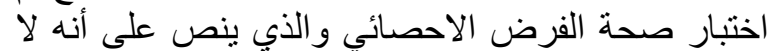

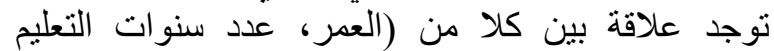

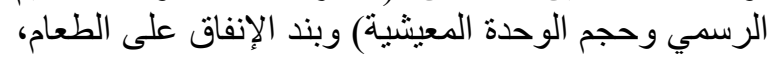

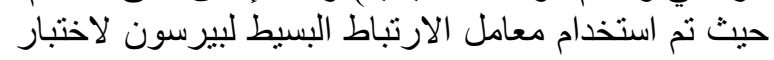
صحة هذه العلاقة.

$$
\text { حيث توضح نتونة العلائج الجدول رقم (8): }
$$

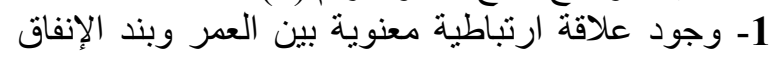

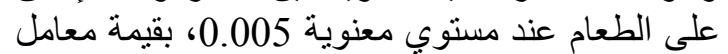

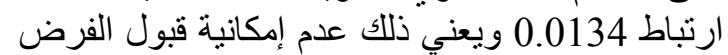
الاحصائي، ووجود علاقة طردية بين المتئ المتغيرين.

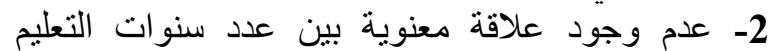

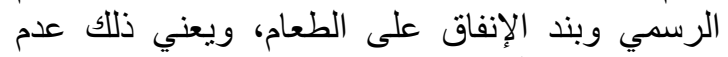
إمكانية رفض الفرض الإحصائي.

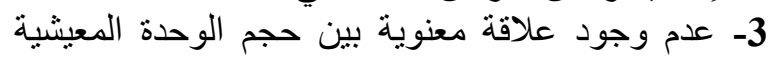

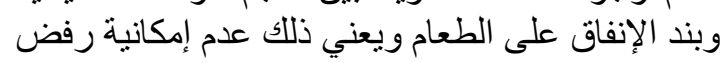

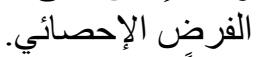

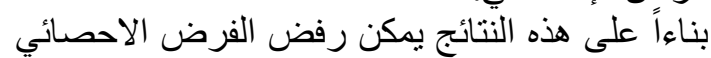
فيما يختص بمتغير العمر، وهو بـاء ما يعني قبول الفرض الفرض

$$
\text { توضح نتائج الجدول رقم (7): }
$$

1- عدم وجود علاقة معنولية بين حجم العمالة وبند الإنفاق

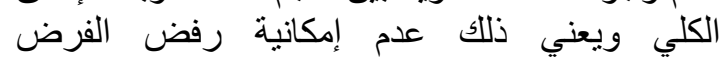
الإحصائي.

2- وجود علاقة ارتباطية معنوية بين حجم الحيازة

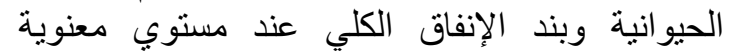

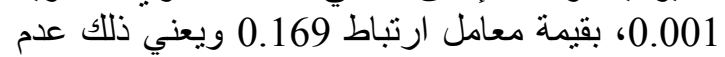

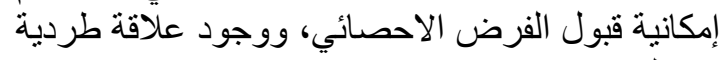

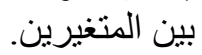
3- وجود علاقية ارتباطية معنوية بين حجم حيازة

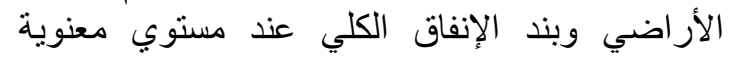

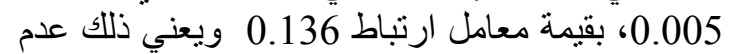

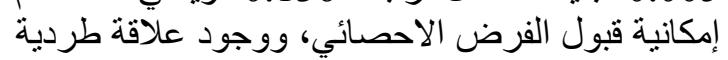
بين المتغيرين.

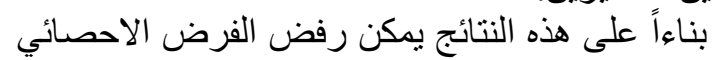

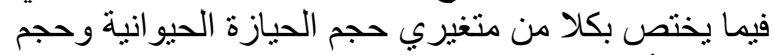

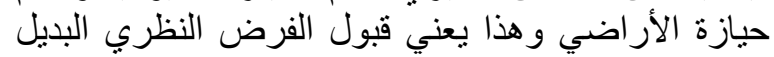

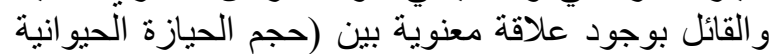

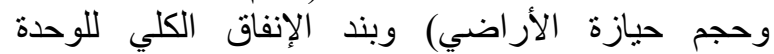

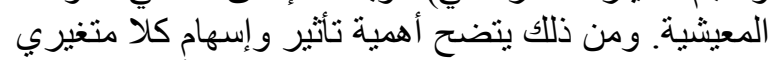

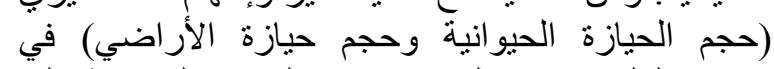
الإنفاق الكلي، حيث كلما زاد حجم الحيازة الحيوانية الإنية كلمًا

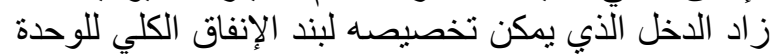

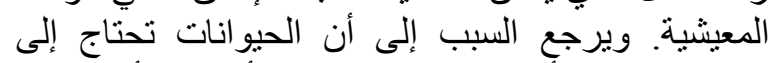

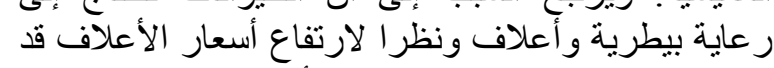

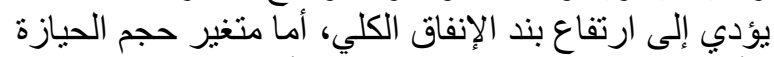

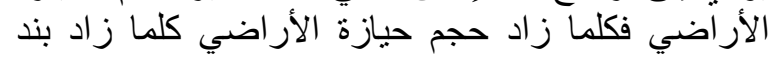

\begin{tabular}{|c|c|c|}
\hline مستوي المعنوية المحسوية & قيمة معامل بيرسون للارتباط البسيط & الخصائص الاجتماعية \\
\hline .015 & $.134^{*}$ & 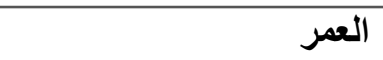 \\
\hline .383 & .049 & عدد سنوات التعليم الرسمي \\
\hline .368 & .050 & حجم الوحدة المعيشية \\
\hline
\end{tabular}

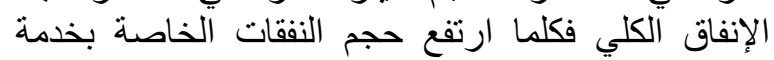


العمالة بالوحدة المعيشية وبند الإنفاق على الطعام، فقد

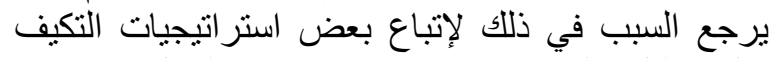

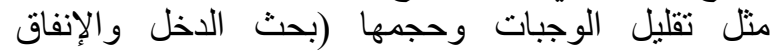
والاستهلاك (الجهاز المركزي للتعبئة و والاحصاء،

. (2013/2012

\section{0. كمال المراجع}

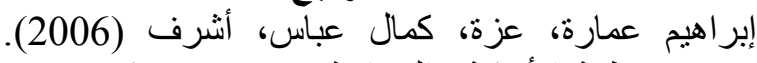

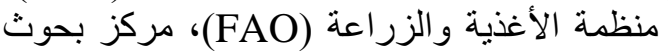

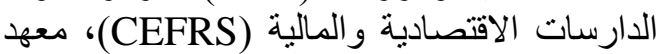
بحوث الاقتصاد، كلية الاقتصاد العلوم السياسية.

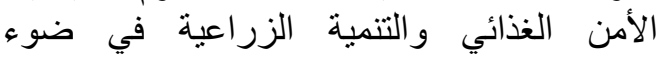

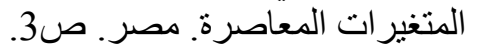

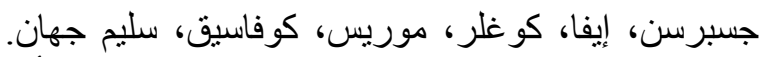
(2015). تقرير التنمية البشرية. منظمة الأمم

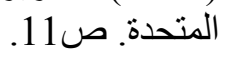

الجهاز المركزي للتعبئة والاحصاء. (2016). كتاب

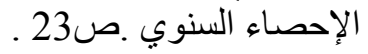

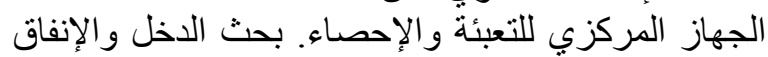

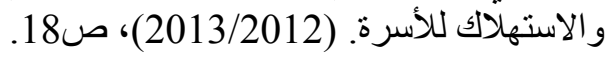

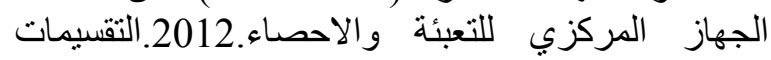
الإدارية و المحية بالجمهورية للمحافظة الثرقية.

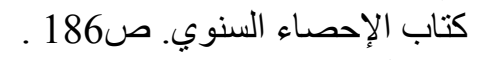
رمضان، رشا (2015). تقرير عن تحديات الطلب
النظري البديل و القائل بوجود علاقة معنوية بين العمرو بند

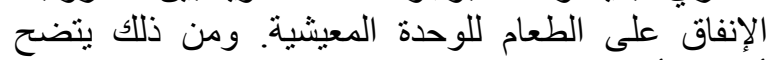

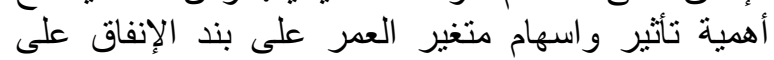

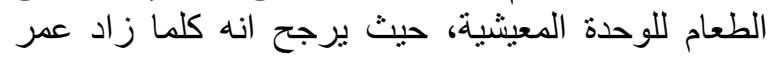

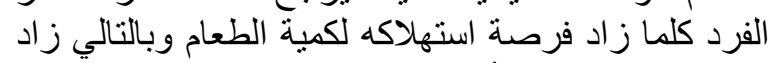

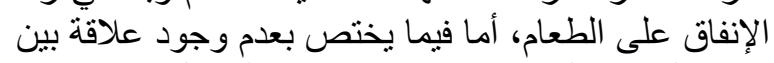

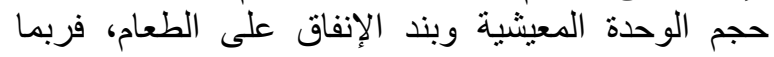

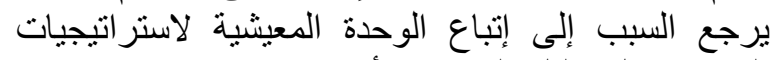

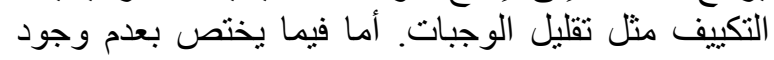

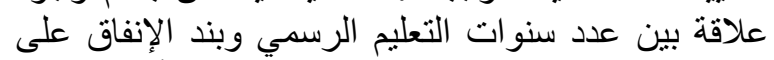

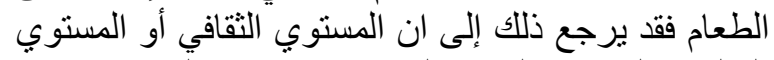

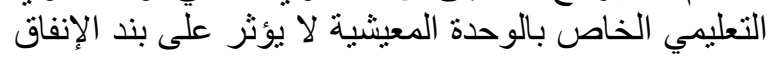

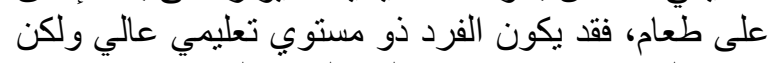

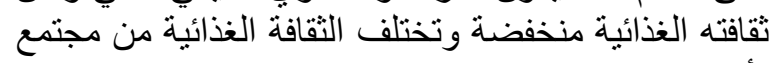
لأخر. العلاقة بين بعض الخصائص الاقتصادية وبند الإنفاق

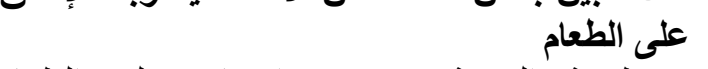

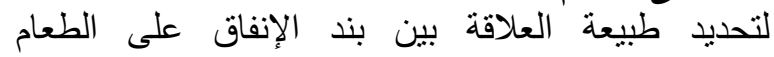

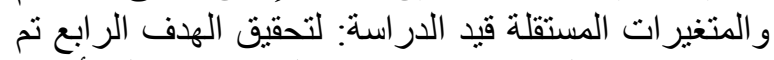

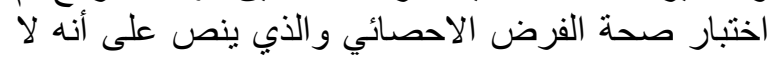

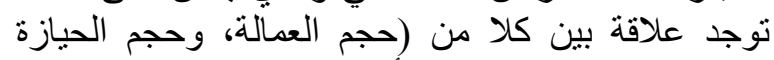

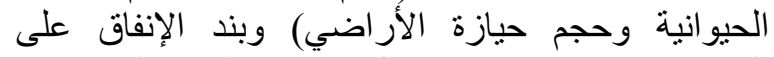

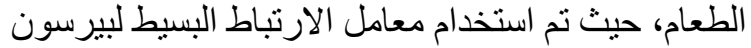
لاختبار صحة هذه العلاقة.

\begin{tabular}{|c|c|c|}
\hline مستوي المعنوية المحسوبة & قيمة معامل بيرسون للارتباط البسيط & الخصائص الاقتصادية \\
\hline .556 & .033 & حجم حيازة الأراضي \\
\hline .209 & .070 & حجم الحيازة الحيوانية \\
\hline .073 & .100 & المعيشية (حجم العمالة عملا رئيسيا للوحدة \\
\hline
\end{tabular}

المصدر: تحليل بيانات الاراسة.

و العرض للآمن الغذائي. المركز المصري

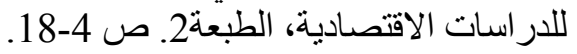
معهد بحوث الإنتاج الحيواني. (2001). بيانات غئن غير منشورة، الاقي.

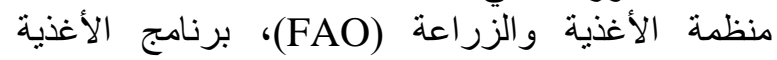

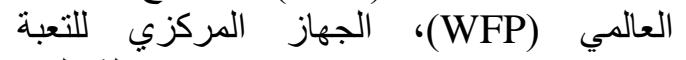

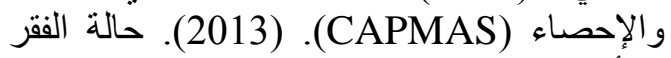

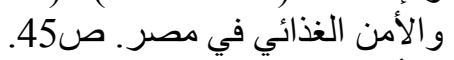

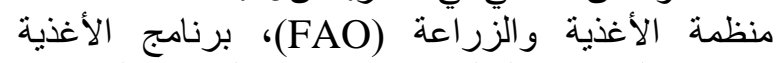

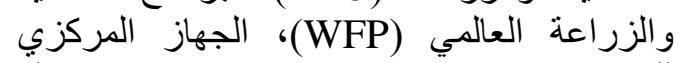

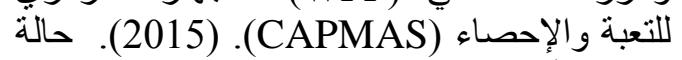
الفقر و الأمن الغذائي في مصر. ص 24.
توضح نتائج الجدول رقم (9): 1- عدم وجود عائ علاقة معنوية بين أي من (حجم حيازة

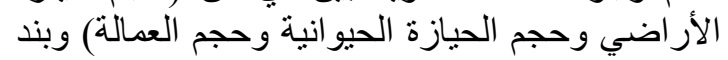

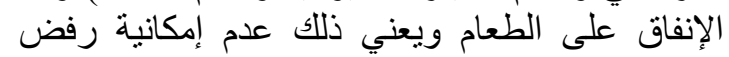
الفرا على الاحصائي.

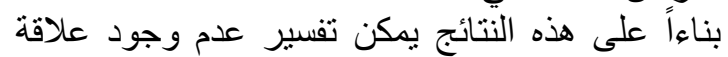

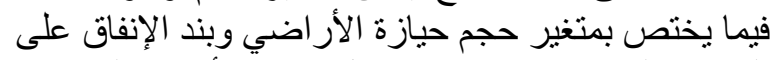

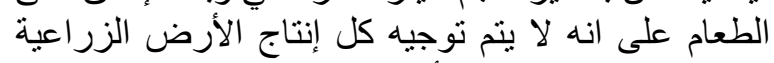

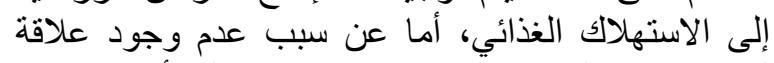

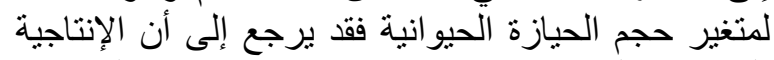

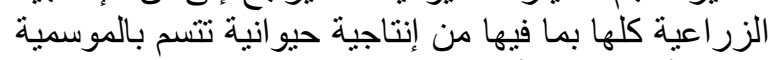

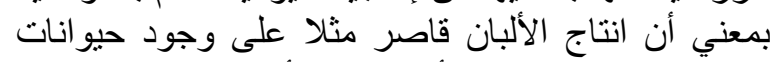

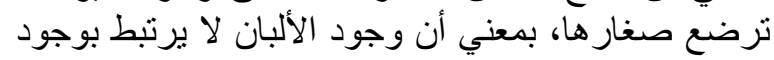

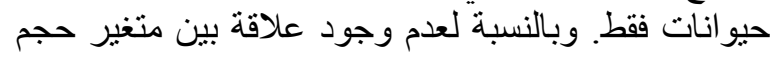

